\title{
PERDA DA ESPONTANEIDADE DA AÇÃO: O DESCONFORTO DE HOMENS QUE SOFRERAM INFARTO AGUDO DO MIOCÁRDIO*
}

\author{
UNDERGOING LOSS OF SPONTANEOUS ACTION: THE DISCOMFORT \\ EXPERIENCED BY MEN HAVING SUFFERED ACUTE MYOCARDIAL INFARCTION
PERDIDA DE LA EXPONTANEIDAD DE LA ACCION: EL DESCONFORTO DE HOMBRES QUE SUFRIERON INFARTO AGUDO DEL MIOCARDIO

\author{
Fernanda Carneiro Mussi** \\ Maria Sumie Koizumi*** \\ Margareth Angelo*** \\ Marlito Souza Lima****
}

Mussi FC, Koizumi MS, Angelo M, Lima MS. Perda da espontaneidade da ação: o desconforto de homens que sofreram infarto agudo do miocárdio- Rev Esc Enferm USP 2002; 36(2): 115-24.

\begin{abstract}
RESUMO
Considerando que conforto - cuja promoção é uma das metas centrais da enfermagem -- e desconforto devem ser entendidos à luz das interações vivenciadas pelo paciente - e, portanto, vinculadas aos fatores objetivos das instituições, da nacionalidade e práticas que as fundamentam - este estudo investigou os significados de conforto e desconforto na perspectiva de homens que sofreram infarto agudo do miocárdio (IAM). Recorrendo ao Interacionismo Simbólico e à metodologia da Teoria Fundamentada nos Dados, entrevistas foram feitas com 13 homens que sofreram IAM, em duas unidades de saúde na cidade de São Paulo. A análise permitiu construir um modelo teórico daqueles significados nessa experiência, caracterizada por três fenômenos e essencialmente permeada pelo desconforto de "padecer a perda da espontaneidade da ação ". Este artigo resume o processo psicossocial básico da experiência, discutindo suas implicações para questionar o modelo clínico de intervenção, apontando a possibilidade de a enfermagem atuar na prevenção e propondo questões para aprimorar a formação do enfermeiro.
\end{abstract}

PALAVRAS-CHAVE: Cuidados de conforto. Infarto do miocárdio. Interação social. Relações interpessoais. \begin{abstract}
Considering that comfort and discomfort must be understood in the light of patients' interactions during illness and treatment - thus linked to institutions' objective factors, grounding rationale, and practices -, this study inquired on comfort and discomfort such as experienced by men who had suffered acute myocardial infarction (AMI). By resorting to the Symbolic Interactionism and to Grounded Theory methodology, data were collected by means of interviews with 13 men who had suffered AMI, at two health units in the city of São Paulo. The analysis led to building a theoretical model of such experience, made up by three phenomena and essentially pervaded by the discomfort of "undergoing loss of spontaneous action". This articles sums up the basic psychosocial process that emerges from that experience, and discusses its implications to question the clinical model of treatment, pointing to prevention as a further scope of action for nurses, besides raising issues to enhance nurse education.
\end{abstract}

KEYWORDS: Comfort care. Myocardial infarction. Social interaction.Interpersonal relations.

\section{RESUMEM}

Considerando que conforto - cuya promoción es una de las metas centralés de la enfermeria - y desconforto deven ser entendidos a la luz de las interacciones vivenciadas por el paciente e por lo tanto, vinculadas a los factores objetivos de las instituciones, de la racionalidad y de las prácticas que las fundamentan - este estudio investigo los significados de conforto e desconforto en la prespectiva de hombres que sufrieron infarto agudo del miocardio (IAM). Acudiendo al Interaccionismo Simbólico Ya la metodologia de la Teoria Fudamentada en los datos, fueron realizadas entrevistas com 13 hombres que sufrieron IAM en dos unidades de salud en la cuidad de São Paulo. El análisis permitio construir um modelo teórico de aquellos significados en esa experiencia, caracterizada por tres fenómenos y esencialmente condicionada por el desconforto de "padecer la pérdida de la expontaneidad de la accion". Este artículo, resume el proceso psicosocial básico de la experiencia, discutiendo sus implicancias para cuestionar el modelo clínico de intervención, apuntando la posibilidad dela enfermera para actuar en la prevención y proponer ideas para aprimorar la formación del enfermero.

PALABRAS-CLAVE: Cuidados paliativos. Infarto del miocárdio. Social comunicacion. Relaciones interpersonales.

\footnotetext{
Extraído da Tese de Doutorado intitulada: Padecendo a perda da espontaneidade da ação: o desconforto vivenciado por sofreram infarto agudo do miocárdio. Apresentada a EEUSP em dezembro de 2000.

** Enfermeira. Doutora em Enfermagem. Professora Adjunta da Universidade Federal da Bahia (femussi@uol.com-br)

*** Enfermeiras. Professoras Titulares da EEUSP.

**** Filósofo. Professor colaborador dos programas de estudos de Pós-Graduação em Psicologia Social da PUC-SP.

homens que
}

Rev Esc Enferm USP 2002; 36(2): 115-24. 


\section{INTRODUÇÃO}

Durante cinco anos de prática de enfermagem em uma unidade coronariana, convivi com questionamentos e inquietações relacionados ao modelo de atuação da enfermagem e seus desdobramentos, tanto para os enfermeiros quanto para as pessoas que, naqueles momentos de suas vidas, requeriam nosso cuidado profissional. Os modelos de atuação da enfermagem no interior da instituição hospitalar pareciam assumir pelo menos duas configurações: fragmentação do cuidado prestado, reduzindo o paciente à condição de mero objeto de tarefas; e desvio das funções de cuidado aos pacientes para aquelas meramente burocráticas, que não demandavam competência técnico-científica ou de relacionamento interpessoal. Isso, segundo me parecia, ameaçava o princípio de justificativa e legitimação da enfermagem como profissão, qual seja, a promoção do conforto.

Essa vivência fez-me questionar o papel profissional do enfermeiro, levando-me, na época, a decidir cursar o mestrado. Durante o curso, ao discutir as concepções de conforto na literatura de Enfermagem, ficou evidente que conforto era uma meta do cuidado, e um conceito presente em toda a história da enfermagem. Essa idéia, mais os limites práticos já percebidos, levaram-me a indagações sobre as metas que norteiam a atividade do enfermeiro e sobre a visão que a enfermagem tem daqueles que requerem seus cuidados profissionais. Em minha dissertação, fiz um primeiro estudo dos significados e necessidades de conforto de pacientes que haviam sofrido infarto agudo do miocárdio.

A literatura preconiza o papel do enfermeiro como de provisão, promoção, manutenção e restauração do conforto(1-3). A centralidade do conceito, para muitos pesquisadores nacionais e estrangeiros, pode ser estabelecida desde os primórdios da profissão(4_8). Além disso, na prática hospitalar, pude perceber que o conforto é algo esperado pelo paciente no processo de tratamento, e ao mesmo tempo uma preocupação e meta da enfermagem. Pareciam coincidir, assim, a busca do enfermeiro e a expectativa do paciente: conforto faz parte tanto dos referenciais teóricos quanto práticos da profissão. Mas, a prática e meus estudos posteriores também evidenciavam contradições, que me levaram a novas indagações sobre o conforto para a enfermagem.

$\mathrm{Na}$ literatura, as definições de conforto supunham em geral uma situação ideal de saúde(2,9,2); conforto é definido com base em parâmetros externos ao paciente. Uma decorrência de usar definições idealizadas para orientar a prática da enfermagem seria reforçar ainda mais a transformação de seu objeto em imperativo moral, dificilmente realizável. Além disso, supõe que o hospital tenha uma estrutura capaz de promover esse estado de conforto, ou que o enfermeiro seja capaz de promovê-lo, apesar da lógica predominante na instituição hospitalar.

A partir de meados da década de 1980, a literatura da enfermagem enfatiza a importância da pesquisa empírica e do discurso do sujeito, passando a pensar o conforto nessa perspectiva. Conforto foi investigado do ponto de vista de pessoas em situação de saúde e de doença $(5-6-8,3,4)$ Embora ofereçam um avanço importante para o conhecimento do significado de conforto/desconforto na percepção de pacientes e enfermeiros, a maioria desses estudos foi basicamente descritiva. São escassos os estudos que buscam entender como os significados de conforto ou desconforto são produzidos na relação do indivíduo com a doença e com as práticas de saúde.

Em virtude dessa lacuna, propus-me a investigar o conforto na perspectiva das definições dos sujeitos que o experimentam e de sua interação com as práticas dos profissionais que o proporcionam. Optei por compreender o fenômeno no processo de interação do paciente infartado com os diversos objetos sociais. Para pessoas que sofreram infarto, os conceitos relacionados a conforto e desconforto não estão satisfatoriamente desenvolvidos na literatura, nem as relações entre eles foram ainda compreendidas com precisão.

Meu objetivo foi pois compreender as situações vivenciadas por homens que sofreram infarto agudo do miocárdio, por eles definidas como conforto ou desconforto, e desenvolver um modelo teórico que descrevesse esses significados nessa experiência. Inscrevo-me assim nessa linha que continua a deslocar o foco do conforto da ótica institucional para a pessoal, buscando compreendê-lo na perspectiva do cidadão comum que recorre aos serviços de saúde. A escolha de sujeitos tendo sofrido infarto agudo do miocárdio justifica-se ainda não só por minha experiência prolongada em uma unidade coronariana mas, sobretudo, porque as doenças cardiovasculares - que incluem o IAM - representam uma das principais causas de morbimortalidade adulta no país(15).

\section{BASES TEÓRICO-METODOLÓGICAS}

Considerando que o conforto ou desconforto é produto da interação, sua compreensão precisa ser buscada nas interações da pessoa consigo mesma, com aqueles que a circundam durante o tratamento, nas situações que enfrenta. Assim, para entender conforto como estado subjetivo, à luz das interações vivenciadas pelo paciente ao longo de sua trajetória de doença e tratamento - e, portanto, vinculadas aos fatores objetivos das instituições, da racionalidade e práticas que as fundamentam - recorri à perspectiva do Interacionismo Simbólico, empregando a metodologia da Teoria Fundamentada nos Dados. 
As premissas básicas do Interacionismo Simbólico ${ }^{(16)}$ permitem entender que a experiência de conforto ou desconforto está associada às interações que a pessoa estabelece em momentos determinados e explicar a experiência como processo e resultado dessas interações. Tornam evidente, também, que os sentidos de conforto surgem e se modificam nas interações que a pessoa estabelece nas situações vivenciadas (consigo mesma, outros seres, situações e objetos); e que a ação das pessoas, relacionada ao conforto ou desconforto, é baseada nos sentidos que ela atribui às coisas com as quais interage. Com base nessas premissas, conforto/desconforto são considerados termos genéricos ou abstrações, não têm um sentido em si: é a interação que lhes atribui significado. Para conhecer os objetos sociais com os quais a pessoa interage, adotei o método de investigação da Teoria Fundamentada nos Dados (Grounded theory); essa metodologia de coleta e análise sistemática de dados qualitativos permite detectar processos psicossociais e desenvolver modelos teóricos de fenômenos da realidade empírica ${ }^{17}$. No caso, o principal meio de coleta de dados foi a entrevista com sujeitos que haviam sofrido infarto.

O número de entrevistados não foi predeterminado, mas resultou do processo de amostragem teórica, um dos procedimentos da Grounded theory ${ }^{(18-19)}$ a coleta e análise são entrelaçadas e ocorrem simultaneamente, já que a análise vai dirigindo o processo de amostragem. Como a preocupação é com a representatividade das categorias-conceitos que emergem do discurso dos sujeitos, de modo a acumular evidências e maior densidade sobre o fenômeno em estudo, não importa a quantidade de sujeitos. Então, o número de participantes resultou da representatividade dos conceitos que emergiram. Após uma ou mais entrevistas com 13 participantes, foi possível alcançar a saturação teórica das categorias, isto é, verificar repetição de dados e ausência de dados novos e, paralelamente, a crescente compreensão dos conceitos identificados.

Foram, pois participantes deste estudo 13 homens adultos, acometidos por infarto agudo do miocárdio, submetidos a tratamento clínico e/ou cirúrgico, conscientes, em condições de serem entrevistados, em processo de tratamento em duas instituições hospitalares de grande porte situadas no município de São Paulo (uma governamental, especializada em cardiologia, e uma instituição geral e privada). Os sujeitos concordaram, por escrito, em participar da pesquisa. Os aspectos éticos e legais inerentes à realização de pesquisa com seres humanos foram respeitados.

A coleta de dados foi realizada no período de novembro de 1998 a dezembro de 1999, após autorização das instituições. As entrevistas foram gravadas e posteriormente transcritas. Duraram em média uma hora e meia e o número de entrevistas com cada participante variou de uma a duas. As primeiras entrevistas foram iniciadas com questões abertas e norteadoras do estudo, tais como "Fale-me um pouco sobre como é estar aqui na UTI", ou "Fale-me um pouco sobre seu conforto aqui". A partir da análise dos dados iniciais, as entrevistas seguintes tinham questões mais focalizadas, para garantir o esclarecimento e aprofundamento das informações necessárias. As últimas entrevistas visaram compreender melhor o processo de ir e voltar do hospital, tema que tinha emergido de vários entrevistados, para entender o significado que atribuíam ao retorno, tanto ao hospital como à vida cotidiana.

$\mathrm{Na}$ análise dos dados, simultânea à coleta, procede-se mediante três tipos de codificação(18-1920) Na primeira, as entrevistas foram examinadas minuciosamente, linha por linha, para extrair os primeiros códigos; por exemplo:

\begin{tabular}{l|l}
\hline \multicolumn{1}{c|}{ Trecho da entrevista } & \multicolumn{1}{c}{ Códigos } \\
\hline $\begin{array}{l}\text { Eu já vinha com esse problema há uns tempos né só } \\
\text { que eu não queria acreditar né tava negando o } \\
\text { problema. E sempre me dava umas dores } \\
\text { estranhas... }\end{array}$ & $\begin{array}{l}\text { Vindo há um tempo com esses problemas Não } \\
\text { querendo acreditar; Negando o problema Tendo sempre } \\
\text { dores estranhas }\end{array}$ \\
\hline
\end{tabular}

Pelo processo de comparação, os códigos identificados foram agrupados por similaridade e diferença, formando as categorias. 
Quadro 1 - Exemplo do processo de categorização (surgimento da dor)

\begin{tabular}{|c|c|c|}
\hline Código & Subcategoria & Categoria \\
\hline $\begin{array}{l}\text { Não querendo acreditar no problema } \\
\text { Negando o problema } \\
\text { Tendo tirado o corpo fora várias vezes } \\
\text { Não querendo aceitar } \\
\text { Não se entregando } \\
\text { Querendo fazer o melhor, mesmo com dor }\end{array}$ & Não querendo se entregar & \multirow{2}{*}{$\begin{array}{l}\text { Tentando manter as } \\
\text { atividades cotidianas }\end{array}$} \\
\hline $\begin{array}{l}\text { Resolvendo tomar (determinado medicamento) } \\
\text { quando } \\
\text { a dor surgia } \\
\text { Começando a tomar remédios caseiros } \\
\text { Dizendo que sentado ia melhorar }\end{array}$ & $\begin{array}{l}\text { Tentando minorar os } \\
\text { incômodos }\end{array}$ & \\
\hline
\end{tabular}

Com o avanço da análise, as categorias são construídas, recodificadas, combinadas e comparadas entre si. Na última fase, busca-se identificar a categoria central, determinando e validando sua relação com as demais categorias e destas entre si. A categoria central representa o elo de ligação entre todas as outras. Durante a coleta e análise dos dados, também usei memorandos e diagramas, que aumentaram a sensibilidade teórica e ajudaram a dar direção à amostragem teórica. Todo o processo permitiu organizar, confirmar e nomear três fenômenos do estudo, que representam três fases da experiência de um homem com infarto, assim como a categoria central, "Padecendo a perda da espontaneidade da ação".

\section{A experiência vivenciada: três fases, uma categoria central}

As três fases demarcadas, representando os três fenômenos que compõem a experiência analisada, traduzem, essencialmente, uma vivência permeada pelo desconforto: Tendo uma ruptura com a vida cotidiana, Tendo a identidade pessoal suspensa e Reapropriando-se da identidade pessoal carregando as marcas do infarto. O infarto é vivido como um evento que ameaça e impossibilita a vida em várias dimensões, resultando no desconforto central, marcante e comum da experiência, caracterizado pela categoria central. Esta perpassa os três fenômenos da experiência e esse desconforto se inicia na interação com o surgimento dos sintomas, continua durante a hospitalização e permanece durante a vida de todos os dias. A perda da espontaneidade da ação é definida e encontra seu sentido em função das conseqüências que o infarto acarreta - e isso atravessa todas as fases da experiência.

No primeiro fenômeno (Diagrama I), os homens sentem iniciar-se a ruptura com o cotidiano $(1)^{1}$ tendo incômodos - dor, cansaço, falta de ar - que, em geral, surgem e reaparecem; sua reação a estes é (2) tentar manter as atividades cotidianas, fazendo o possivel para não permitir que os incômodos interfiram com o dia-a-dia. Resistem a essa interferência nas ações cotidianas de quatro maneiras: (2.1) não querendo se entregar, (2.2) não associando os incômodos a problema cardíaco, (2.3) tentando minorá-los, (2.4) alimentando esperança de melhorar e (2.5) não procurando atendimento médico.

À medida que os sintomas se intensificam, porém, passam a (3) restringir certas ações, (3.1) restringindo atividades costumeiras ou mesmo (3.2) parando de exercer atividades, (3.3) sentindo-se "diferentes". Até que, quando a dor se torna insuportável, sentem-se (4) dominados pela dor e dãose conta da seriedade do que os afeta, (5) sentindo que a vida está em jogo. Quando a magnitude dos sintomas se intensifica, os homens relativizam o cotidiano e passam a valorizar os incômodos como objeto de interação. O agravamento dos incômodos ou a dor insuportável paralisa sua insistência em prosseguir tentando manter o cotidiano.

Sentindo que a vida está em jogo, mas impotentes para agir eles próprios para recuperá-la, percebem-se (6) dependendo de socorro externo para ter a vida de volta; apelam assim à (6.1) ajuda de outras pessoas, (6.2) de Deus e (6.3) à instituição médico-hospitalar. O socorro a que recorrem pode assumir a forma de uma consulta médica ou ida ao pronto-socorro - quando então confirmam a gravidade da situação e se vêem (7) confirmando o risco de vida que estão correndo, (8) sucumbindo finalmente à hospitalização. Apesar ou devido ao medo, tendo confirmado a doença no coração, não vêem outra saída senão aceitar a hospitalização, para "ter a vida de volta": Ou você fica, ou você morre".

O infarto é vivido como uma ameaça que impossibilita a vida em várias dimensões. É claro que a dor é um enorme desconforto, mas os sujeitos

\footnotetext{
${ }^{1}$ Os números entre parênteses referem-se às categorias: (1); as subdivisões correspondem às subcategorias: (1.1).
} 
enfatizam como negativo, mais que a dor, aquilo que ela os impossibilita de fazer. Assim, o que marca a experiência nessa primeira fase é a ruptura com a vida cotidiana, que culmina na hospitalização. O desconforto nessa fase está, portanto, compreendido no desconforto central, marcante e comum da experiência, caracterizado pela categoria "Padecendo a perda da espontaneidade da ação".

O segundo fenômeno (Diagrama II) inicia-se no interior da instituição médico-hospitalar, onde a experiência do sujeito internado, principalmente na unidade de cuidados intensivos, é caracterizada pelas condições de impotência e medo de morrer. (1) Nada podendo fazer e (2) vivendo a incerteza de ter a vida recuperada, os sujeitos têm por objetos de interação básicos a dor e a ação médica. O cotidiano hospitalar é um espaço e um tempo onde as referências para a ação não são as do âmbito pessoal e da experiência cotidiana, mas as normas e restrições médicohospitalares. Nessa percepção de total impossibilidade de fazer qualquer coisa, o homem se sente como tendo "perdido" a identidade, deixando de ser pessoa -tendo a identidade pessoal suspensa -_para assumir o papel de paciente - e de paciente que "não pode". Interagindo com o protocolo das restrições impostas para o cuidado do coração doente, sente comprometida a ação espontânea segundo a própria racionalidade, seus próprios desejos, impulsos ou escolhas. Abalado pela ruptura com a vida cotidiana (1.1), percebe que a vida no hospital é incompativel com o lazer, o trabalho, a vida familiar e social. (1.2) Vivenciando a imposição de restrições - tendo de ficar no hospital, confinado ao leito, tendo de mudar hábitos, sendo privado de contato com o mundo, tendo a intimidade violada, submetendo-se às recomendações médicas -, o sujeito oscila entre essa sensação de restrição e a persistência, mesmo que minorada, dos sintomas, persistindo assim também o medo de morrer. Pelas restrições que the são impostas, sente-se (1.3) coisificado, reduzido a quadro clínico, infantilizado, não se sentindo considerado como pessoa; na condição de paciente, sente-se inclusive (1.4) privado de informações sobre si próprio e o tratamento.

Por um lado, o "paciente" percebe a adequação das intervenções médicas à dimensão de sua doença mas, por outro, se dá conta que tais intervenções nem sempre contemplam a dimensão do sofrimento humano. A interação com objetos que não passaram por escolha pessoal produz desconforto. Sob a racionalidade médico-científica, a ação é regida não mais pela espontaneidade característica da vida cotidiana, mas por imperativos que devem ser seguidos, sob risco de vida. Portanto, a ação não está, necessariamente, na esfera do sentido e do afeto, mas dos imperativos médicos. Com isso, o sujeito percebe que a identidade pessoal se retrai, sendo sobreposta pela de paciente infartado, que paralisa o exercício da identidade pessoal. Nas interações com a equipe médica, o paciente perde a competência de julgar e agir. Se antes sua ação era espontânea, agora é normatizada; o padecer reside na perda da ação relativamente autônoma que o qualificava como indivíduo, com decisões adultas: aqui a ação é totalmente norteada por uma racionalidade externa a si mesmo. Tendo a identidade pessoal suspensa, o homem padece a perda da espontaneidade da ação em função da sobrevivência - então regulada exclusivamente pela racionalidade instrumental e pelos limites impostos pela doença e internação.

$\mathrm{Na}$ condição de paciente com o coração doente, (2) vive a incerteza de recuperação. Essa incerteza é fonte total de desconforto, pois a alternativa à morte aparece-lhe então como o risco de (2.2) tornar-se improdutivo. E também é alimentada pela falta de controle e pelo desconhecimento sobre o desenrolar da recuperação do coração doente, pelas dúvidas sobre o que poderá acontecer na trajetória de tratamento. Aqui, desconforto é também fruto da constatação de que a vida depende de ações externas a si mesmo. Enquanto dura a hospitalizacão, vive objetivamente (2.1) dependendo de prazos e decisões médicas, (2.3) sentindo novas dores juntar-se à dor no peito, as quais nem sempre podem ser evitadas, pois são decorrentes das demandas de tratamento. Vê-se (2.4) tendo a vida controlada por equipamentos e teme, assim, a falha desse controle externo. Interage ao longo de sua experiência de infartado com diferentes possibilidades de tratamento, as quais vão se modificando durante a evolução da doença e resultam na vivência da incerteza progressiva da recuperação da vida, fazendo com que se sinta, continuamente, oscilando entre (2.5) vislumbrar soluções e (2.6) quase não vislumbrá-las. A insegurança da sobrevivência se acentua à medida que se vê já tendo desenrolado todo o fio do carretel terapêutico. Pode vivenciar uma seqüência ou alternativa de interações durante a trajetória de tratamento: confiar na eficácia dos procedimentos médicos, contar com a possibilidade de solução vivendo a expectativa da cirurgia, agarrando-se a um fio de esperança, não realizando a esperança depositada na cirurgia e, no limite, sentindo-se quase sem possibilidade terapêutica. Sabendo que corre risco de vida, submete-se a alternativas sempre promissoras para conter o perigo da doença. Pode achar que vai morrer (2.7), toma consciência de que o corpo é mortal, a despeito da vontade, do tempo ou espaço. A percepção da vulnerabilidade também emerge vendo outros morrerem. Define a unidade de cuidados intensivos como local onde se corre risco de vida; e, também, identifica riscos aos quais se vê exposto por se sujeitar ao tratamento. Assim, vislumbrando a chance de recuperação ao optar pelo tratamento, também sofre o medo de suas conseqüências contrárias, se não tiver acesso a qualidade técnica de atendimento. Aqui, 
reconhecendo sua susceptibilidade ao risco, o padecimento tem dois sentidos: a incerteza da recuperação e a não recompensa do sofrimento imposto nesse periodo da experiência.

Mas, embora paciente, o homem não fica totalmente passivo. Empreende diversas estratégias (3) tentando conservar a existência. Assim, quando se sente ameaçado e impossibilitado de objetivações do self, (3.1) resistem, (3.2) buscando segurança ou simplesmente (3.3) tolerando. Tais estratégias incluem desde o autoconvencimento a se resignar às restrições até a transgressão das normas -- de que um exemplo extremo é a fuga do hospital. Resistir é ficar só querendo ir embora, pensar em fugir, camuflar sintomas, transgredir normas, ou questioná-las por estar sem dor. Aqui, o que pode ser lógico para o tratamento pode ser completamente ilógico para esse homem, quando julga as prescrições médicas a partir de sua experiência com a racionalidade prática da vida cotidiana. E certo que, na maioria das vezes, aquele que transgride já não sente mais dor. A medida que sua condição de saúde melhora, que deixa a UTI, passa a questionar mais as restrições impostas. Usa a dor como critério para orientar decisões: na ausência de dor, sente-se capaz, acreditando que o coração não precise mais de tanta cautela. Mas, se a ausência de dor promove segurança e conforto, porque alivia o medo e descongela a ação, também é verdade que intensifica o desconforto em relação à submissão aos controles médicos. Ao tentar um papel menos passivo e mais espontâneo, percebe que o controle médico acentua a vigilância, passa a cercar mais de perto sua ação e, quase sempre, esse homem se vê sofrendo conseqüências da transgressão.

Ao mesmo tempo, porém, nunca se coloca em risco total, pois sempre age buscando segurança, na tentativa de evitar que algo no tratamento passe desapercebido de avaliação e intervenção. Sempre age preservando e protegendo a própria vida, mesmo quando age contra a norma médica. Busca, continuamente, interagir com elementos que indiquem que está sendo tratado em um lugar seguro, por pessoas confiáveis e competentes. Enquanto teme o que possa resultar da ação médica, busca pistas para convencer-se a confiar na equipe médica. Torna-se observador da linguagem, do comportamento, do gesto e do olhar dos profissionais. A atenção que dispensa à ação da equipe (por exemplo, a equipe discute, checa, faz controles, intervém) corresponde à atenção com a qual ele mesmo se autovigia. Nenhum olhar é mais atento que o próprio olhar, o olhar que deseja a própria vida.

$\mathrm{Na}$ verdade, nessa fase, os homens referem-se a apenas duas experiências de conforto. Este é experienciado quando reconhecem a qualidade técnica do atendimento, constatando que sua sobrevivência está assegurada pela ação da equipe da instituição hospitalar; sentem-se confortados pela oportunidade de usufruir da qualidade desse atendimento técnico: nesse caso, conforto é confiança. A outra experiência de conforto referida é a da possibilidade de interagir com o mundo à sua volta, especialmente as oportunidades de relações intersubjetivas. Ser tratado como pessoa, receber visitas, usufruir de conversas informais com a equipe que o atende é o que mais contribui para minimizar o padecimento central dessa fase, que é o da suspensão da identidade pessoal.

Embora alguns homens infartados resistam a essa suspensão, outros, durante a internação, sofrem calados tentando tolerar as privações. Sua passividade consiste na ausência de ação que demonstre combate, ou queixa do que o restringe, aprisiona, congela a ação. Resigna-se em função das garantias de vida e, nesse sentido, essa reação de tolerância não reflete apenas passividade, mas ação efetiva para atingir a finalidade de recuperação da vida. Resistindo ou não, todos os homens toleram a suspensão do exercício da identidade, mantendo força pessoal para suportar o tratamento. Em suma, ao longo da internação, transitam entre resistir e tolerar - as restrições, a sensação de impotência, a incerteza de ter a vida recuperada. $\mathrm{E}$, aos poucos, vêem atenuarem-se as restrições, monitorando a expectativa de alta, alimentando esperança de melhora.

No periodo imediatamente anterior à alta, o desconforto da impotência e da incerteza de recuperação diminui. Ao mesmo tempo, retomam-se as relações intersubjetivas suspensas no início do tratamento e maior é o conforto. Ainda que nos limites do pós-infarto, o homem percebe-se pouco a pouco reapropriando-se de si mesmo, passando também a antecipar a vida após a alta (3.4). Mas, ao projetar o modo de preservar a vida, confronta-se com um paradoxo: o desejo de assumir a vida tal como antes do infarto, contrapõe-se à intenção de submeter-se às normas médicas para poder preservar a vida. Começa a julgar a vida em busca de caminhos para sobreviver; julgando racionalmente o cotidiano, passa a aceitar padrões de comportamento a serem adotados daí para frente. E, entretanto, transita para a vida cotidiana com a insegurança da "cura", a imprevisibilidade do que pode acontecer, o temor do retorno da doença.

O terceiro fenômeno (Diagrama III) compreende o fim do período de internação e a volta ao lar. Ao sair do hospital, a experiência é de contentamento, da ilusão da "cura", do alivio por ter sobrevivido. Ao retornar à vida cotidiana, o homem vê reconquistada a chance de ser ativo outra vez, vai (1) tentando levar a mesma vida de antes. O medo de morrer, que antes era um dos principais objetos de interação, é relativizado, porque (aparentemente) cessou a ameaça à vida. Conforto é poder reapropriar-se das dimensões fundamentais da vida cotidiana, incompativeis com o período de internação: a vida social e familiar, o 
exercício da sexualidade, o trabalho, o lazer - (1.1) recuperando o cotidiano com alegria. Ao retornar, dono de si mesmo outra vez, busca um campo de exercício de sua identidade como homem infartado. Nesse confronto com o cotidiano, o sujeito passa por um período inicial de ajuste (1.2), pois ainda precisa restaurar as forças e o vigor para sentir-se em melhores condições de retornar às atividades usuais. Quando não sente, ou quando desaparecem eventuais limites fisicos, ele acredita que pode retomar à mesma vida de antes (1.3). Assim, a opção pela forma de viver o pós-infarto deixa de ser norteada pela racionalidade médica e desloca-se para a dimensão pragmática da vida cotidiana. O esquecimento ou a violação das regras médicas dependem da reação do corpo às diversas atividades do dia-a-dia.

No entanto, ao perceber os novos limites do corpo ou sentir reaparecerem os sintomas, vê que o desconforto o acompanhou à casa. Sentindo reaparecerem sintomas, nas relações cotidianas, confirma as novas fronteiras que o corpo não pode ultrapassar. As marcas do infarto começam a pesar e o homem volta a sentir-se prejudicado para agir espontaneamente, não só pelos limites do corpo como também pelo medo do que possa acontecer. Diante dos limites da condição de infartado, vai se pondo à prova, para ver quanto o coração é capaz de suportar e como vai direcionar suas ações. Ao longo do tempo, vai confirmando a permanência dos limites da condição de infartado, até que, em algum momento de sua trajetória, revive a doença. (2) Tendo retorno da doença, o sujeito revive toda a trajetória anterior, incluindo a hospitalização e o processo de suspensão da identidade pessoal - porém dessa vez com o agravante da maior consciência do risco e incerteza de recuperação. O retorno da doença traz não só a interação com a dor, mas sobretudo, com a insegurança.

Após a segunda saída do hospital, os sujeitos começam a dimensionar racionalmente ações que antes eram espontâneas (pois não precisavam pensar antes de agir, não era necessário prever possiveis danos de atos cotidianos) e, assim, (3) regulam a ação pelos limites do corpo e da norma médica. Eles, então, (3.1) interiorizam as normas médicas, mesmo porque sentem e adquiriram consciência dos limites do corpo. Se o início do processo de reapropriação da vida era marcado pela euforia de possibilidades, agora padecem porque vivem o desconforto da privação do exercício de si mesmo e da internalização forçada dos limites como marca da identidade pessoal. Assim, o diálogo com o que deve ou não fazer os remete, novamente, à própria impossibilidade; as ações que antes eram espontâneas agora são cercadas de cautela, proteção, previsão: passam pelo crivo de sua validade para conservação da existência e pelo medo da morte. Ceder à norma médica significa sacrificar a própria espontaneidade, na esperança de assegurar a existência por um tempo maior. O infarto traz impacto na vida produtiva (3.2) e privada (3.3), levando-os a mudar hábitos alimentares, restringir a vida sexual, limitando o lazer e outras atividades e, no limite, tornando-se dependentes; trabalham menos, mudam de ramo e, no limite, aposentam-se e param de trabalhar. Assim, reapropriar-se da identidade pessoal carregando as marcas do infarto implica o desconforto cujo sentido se expressa por padecer a perda da espontaneidade da ação cotidiana, em função da sobrevivência regulada pela norma médica e pelos limites do corpo e da mente.

Essa marcas do infarto o fazem demarcar um limite temporal entre a vida de antes após o infarto, onde a primeira se torna um valor maior que a vida atual - (4) Constatando que a vida mudou. Embora esse processo de padecimento e desconforto seja objetivado em limites, implica também um processo de reação em função da conservação da existência como pessoa. (4.1) Reagindo às marcas do infarto, os homens expressam, em momentos e graus variados, conformismo e inconformismo. Entretanto, inconformando-se ou conformando-se, valorizam a condição de estar vivo e da vida possivel. As marcas da condição de infartado, ainda que provoquem intenso desconforto e concretizem a impossibilidade de voltar à vida de antes, não retiraram a possibilidade de existir. Vivem, então, (4.2) apegandose à vida, buscando e encontrando razões para viver, encontrando sentido no sofrimento e sentindo-se solidários com o sofrimento alheio.

$\mathrm{Na}$ cotidianeidade, na reapropriação da identidade pessoal com as marcas do infarto, $\mathrm{O}$ conforto é limitado: aparece apenas ligado a momentos de trocas intersubjetivas, ao prazer de certas ações que não implicam risco de agravamento da doença ou de morte. A experiência predominante, contudo, é o desconforto de padecer a perda da espontaneidade da ação, em função da sobrevivência regulada pela norma médica e pelos limites que a doença impõe.

Assim, este modelo descreve a experiência do homem infartado como a do padecer que impede o ser espontâneo no cotidiano, em que praticamente qualquer ato tem de ser remetido ao julgamento racional, com base na normatização médica, para ponderar o risco de vida que acarreta. O sentido e a objetivação do desconforto, na experiência vivida, é "Padecendo a perda da espontaneidade da ação".

\section{DISCUSSÃO E REFLEXÃO}

Esta investigação suscitou reflexões sobre lacunas da enfermagem em promover conforto e sobre uma contradição entre o conhecimento médico e a intervenção, as quais têm implicações para a prática e o ensino da enfermagem. 
Vimos como, na situação de internação, conforto é associado às raras possibilidades de interação interpessoal (em que o sujeito é considerado como pessoa) e à constatação de que sua sobrevivência "está em boas mãos", ou seja, da qualidade técnica do atendimento a ele dispensado. A experiência dos homens aqui investigados mostra que o conforto não está, essencialmente, relacionado com os padrões de hotelaria vendidos pelo hospital-empresa, nem tampouco com sua racionalidade funcional, onde a divisão do trabalho ou a insuficiência de recursos humanos impossibilitam interações intersubjetivas e coisificam os indivíduos. Durante a hospitalização, o conforto proporcionado por trocas intersubjetivas foi praticamente ausente.

Nesse sentido, uma questão importante suscitada por esta investigação é a unidimensionalidade da intervenção médica. Três séculos depois de Descartes, a medicina em sua intervenção ainda se baseia nas noções de corpo como máquina, da doença como conseqüência de uma avaria na máquina, e da tarefa do médico como de "conserto". Hoje, o saber médico já extrapola essa concepção meramente mecanicista, na medida em que considera fatores psicológicos e sociais da doença. Contudo, parece continuar cartesiano na ação imediata: é unidimensional quando centra a intervenção apenas para consertar a "parte danificada" do corpo.

A experiência analisada mostra que a busca do conforto, na lógica da racionalidade médicohospitalar, centra-se muito mais nas interações com a esfera da tecnologia e do controle do que nas relações interpessoais. Acredito que o processo de tratamento não deva apenas pensar conforto como recuperação da dimensão mecânica, fisiológica, do indivíduo. No entanto, no modelo médico-hospitalar predominante, isso nem sempre é possivel.

Vemos na história da enfermagem que, para a profissão justificar-se como prática nas sociedades industriais, racionalizadas e normativas, foi levada a aceitar a racionalidade médico-científica ${ }^{(21)}$. Ao fazêlo, a enfermagem deixou para trás aspectos de sua história que visavam resgatar a subjetividade do ser humano. E deparou-se com impedimentos para pensar sua atuação em prol do conforto em outras dimensões. Assim, tornou-se também unidimensional, na medida em que ficou atrelada ao saber e trabalho médicos.

$\mathrm{Na}$ literatura contemporânea, o objetivo da enfermagem de promover conforto continua sendo enfatizado. Mas a ordem hospitalar, desde sua origem, aponta para uma noção de conforto baseada na racionalidade funcional, econômica e científica, e não para gerar conforto na ótica dos usuários. Como a enfermagem historicamente parece adequar-se às finalidades institucionais, essa noção funcional de conforto prevalece. Para os enfermeiros, os conflitos são inúmeros, pois a literatura que orienta sua formação e lhes apresenta os critérios de avaliação da ação ou do serviço não vincula metas e critérios à ordem tecnológica, racional e econômica da instituição. Há portanto um descompasso entre o papel do enfermeiro como confortador, preconizado pela literatura de enfermagem, e a ordem hospitalar, que nem sempre oferece condições para o desempenho desse papel(22).

Quero enfatizar que não questiono a importância da tecnologia colocada à disposição da manutenção da vida humana. A intervenção médica salva a vida. Mas a questão que se coloca aqui não é a renúncia aos méritos da racionalidade: é a da recuperação de outras dimensões do ser humano na atividade da enfermagem, que o modelo clínico e a ordem hospitalar freqüentemente negligenciam. Defendo que o enfermeiro, em suas interações, não privilegie apenas a técnica, mas valorize a solidariedade e a humanidade nas trocas intersubjetivas.

Por outro lado, vimos como o desconforto perpassa toda a experiência do sujeito, desde a dor e o medo de morrer, passando pela vivência do próprio infarto e da condição de paciente, até o confronto com suas impossibilidades, no retorno à vida cotidiana. E como, ao final da hospitalização, o sujeito insiste em tentar voltar à mesma vida de antes. Esse comportamento repõe a situação original, isto é, os homens tendem sempre a ter retorno da doença e voltar ao hospital (com exceção dos três entrevistados que acabavam de ter sofrido o primeiro infarto, todos os demais tinham tido retorno da doença e estavam hospitalizados para submeter-se a tratamentos, cirurgia, ou para tratar um novo infarto).

Se a literatura médica tem razão em estabelecer relação de causa e efeito entre o infarto e o estilo de vida de um indivíduo, fica claro que, se este, após o primeiro infarto, mantiver o mesmo estilo de vida de antes, está sujeito a ter um segundo, ou ao agravamento da doença. O tratamento médico-hospitalar é indubitavelmente eficiente. Mas o fato de homens que já tiveram infarto insistirem em retomar a mesma vida de antes sugere que o tratamento não privilegia uma atuação voltada a mudanças no seu estilo de vida. A ação médica parece não lograr resultados em tentar demovê-los da ilusão de que poderiam assumir "vida normal".

Essa forma de intervenção é incompativel com as próprias pesquisas médicas que destacam os fatores de risco psicossociais para as coronariopatias, revelando incoerência com sua preocupação de prevenção. Parece haver uma contradição na racionalidade médicocientífica, entre a constatação dos indicadores de risco para o infarto e o tratamento hospitalar, que não inclui uma dimensão eficaz de prevenção. Obviamente, não se pode atribuir exclusivamente à área médica a responsabilidade pela prevenção. Sabendo que esses fatores de risco estão associados às condições de vida na sociedade atual, a prevenção deve extrapolar a área médica para outros setores, como a saúde pública e o próprio mundo do trabalho ${ }^{(22) .}$ 
E a prevenção também estaria vinculada ao conforto do homem infartado, após a hospitalização: ele poderia ter menos desconforto se pudesse dispor de uma ação pedagógica mais eficaz, que o ajudasse a encontrar, no âmbito de suas possibilidades, uma nova forma de ser e de viver, para que o cotidiano não fosse construído em torno da doença e da negatividade. Talvez as perdas do infarto pudessem ser relativizadas, se os homens fossem ajudados a refletir e desvencilhar-se desse foco sobre sua particularidade, buscando outras motivações para a vida. Por exemplo, dada a centralidade do trabalho em suas vidas, e o fato de o infarto muitas vezes incapacitá-los para o mesmo, ou contra-indicar o exercício de certos trabalhos, uma atuação pedagógica preventiva poderia levá-los a refletir sobre aspectos de sua atividade produtiva e de seu comportamento e a alterá-los, ampliando seu leque de alternativas de reconstrução do cotidiano. Este poderia ser um outro espaço para a intervenção da enfermagem, se o enfermeiro atuasse também na esfera preventiva e educativa (22).

Para tanto, seria necessário um trabalho de base no processo de formação dos profissionais de saúde, com vistas à ruptura com a concepção cartesiana de doença e intervenção médica, o que implica colocar em cheque os conteúdos curriculares. Seria ideal propor um processo contínuo e efetivo de intervenções pedagógicas para a prevenção primária e secundária, a comunicação e interdisciplinaridade da ação, buscando colocar a ciência a serviço dos homens, no sentido de se libertarem do que os aprisiona e restringe por falta de conhecimento.

Tomar a promoção do conforto como um objetivo da enfermagem sem que a formação esteja voltada para possibilitar aos enfermeiros desenvolver uma visão mais crítica de seu campo de atuação, da lógica que rege o sistema hospitalar, é tornar a promoção do conforto apenas um elemento do discurso normativo, e não, de fato, um objetivo de intervenção da enfermagem. Tomar o conforto como objeto da ação da enfermagem significa repensar a formação do enfermeiro, oferecendo ao profissional condições para comunicar-se com outras áreas do saber, para que esse objetivo não seja incorporado apenas como obrigação moral, desligada de racionalidade crítica. A formação deveria assegurar ao enfermeiro oportunidades de refletir sobre a ordem tecnológico-administrativa hospitalar atrelada à racionalidade médico-científica, para questionar a ótica unidimensional de promoção do conforto, tornando a enfermagem mais abrangente e eficaz nessa promoção. Repensar a formação inclui centrá-la nas questões éticas e políticas da profissão, para assegurar a melhor compreensão do papel social do enfermeiro(22).

Uma visão holística possibilitaria ao enfermeiro o reconhecimento da pessoa, antes que corpo doente ou paciente. Possibilitaria a construção de um conhecimento ético a serviço da recuperação da humanidade do homem. Um enfermeiro assim formado seria um profissional consciente dos determinantes sociais, políticos, históricos e ideológicos da profissão, para a crítica e a ação efetiva no contexto das práticas de saúde.

\section{REFERENCIAS BIBLIOGRÁFICAS}

(1) Goodnow M. La técnica de cuidar enfermos. 4nded. Buenos Aires: Procuro; 1950. El conforto del pacient;107-36.

(2) Francis GM, Munjas B. Promoting psychological comfort. 2"ded. Dubuque: Brown; 1979-

(3) Du Gas BW. Enfermagem prática. 4nd ed. Rio de Janeiro: Guanabara; 1984. Necessidades de conforto, sono e repouso;311-29.

(4) Jacox AK. Key aspects of confort. In: Funk SG, editor. Key aspects of comfort: management of pain fatigue and nausea. Nova Iorque: Springer; 1989. p.8-21.

(5) Morse JM. An ethnoscientific analysis of comfort: a preliminary investigation. Nurs Pap 1983; 15:6-20.

(6) Morse JM, Bottorff JL, Hutchinson S- The paradox of comfort. Nurs Res 1995; 44:14-9.

(7) Kolcaba KY. A taxonomic structure for the concept of comfort. Image J Nurs Sch 1991; 25:237-40.

(8) Arruda EN, Larson PJ, Meleis AI. Comfort: immigrant hispanic cancer patients' views. Cancer Nurs 1992;15:387-94.

(9) Fischer VG, Connoly AF. Promotion of physical comfort and safety. 2n ${ }^{d}$ ed. Dubuque: Brown; 1975. Synthesis; 91-5.

(10) White DT. Fundamentos de enfermagem. São Paulo: EPU; 1976. Paciente e enfermeira frente a frente; 49-55.

(11) Elhart D. Princípios científicos de enfermagem. Lisboa: Livros Técnicos e Científicos; 1983. O âmbito de intervenção de enfermagem no apoio à adaptação; 288-96.

(12) Engelking C. Comfort issues in geriatric oncology. Semin Oncol Nurs 1988; 4:198-207.

(13) Hamilton, J. Comfort and the hospitalized chronically ill. Gerontol Nurs 1989; 15:28-33.

(14) Mussi FC. Conforto: significados e necessidades na perspectiva do paciente com infarto agudo do miocárdio[dissertação] São Paulo (SP): Escola de Enfermagem da USP; 1994.

(15) Laurenti R, Buchalla CM, Caratin CVS. Doença isquêmica do coração: internações, tempo de permanência e gastos; Brasil, 1993 a 1997. Arq Bras Cardiol 2000; 74: 483-87.

(16) Blumer H. Symbolic interactionism: perspective and method. Englewood Cliffs [NJ, EUA]: Prentice Hall; 1969.

(17) Chenitz WC, Swanson JM. From practice to Grounded Theory. Menlo Park [CAL, EUA]: Addison-Wesley; 1986. Qualitative using grounded theory; 3-15.

(18) Glaser BG, Strauss AL. The discovery of Grounded Theory: strategies for qualitative research. Nova Iorque: Aldine; 1967.

(19) Glaser BG. Theoretical sensitivity. Mill Valley [CAL, EUA]: Sociology Press; 1978.

(20) Strauss AL, Corbin J. Basics of qualitative research: Grounded Theory procedures and tecniques. Newbury Park [CAL, EUA]: Sage Publications; 1991.

(21) Almeida MCP, Rocha JSY- O saber de enfermagem e sua dimensão prática. São Paulo: Cortez; 1986.

(22) Mussi FC. Padecendo a perda da espontaneidade da ação: o desconforto vivenciado por homens que sofreram infarto agudo do miocárdio. [Tese] São Paulo (SP): Escola de Enfermagem da USP; 2000.

\section{Artigo recebido em 25/09/01}

Artigo aprovado em 16/09/01 


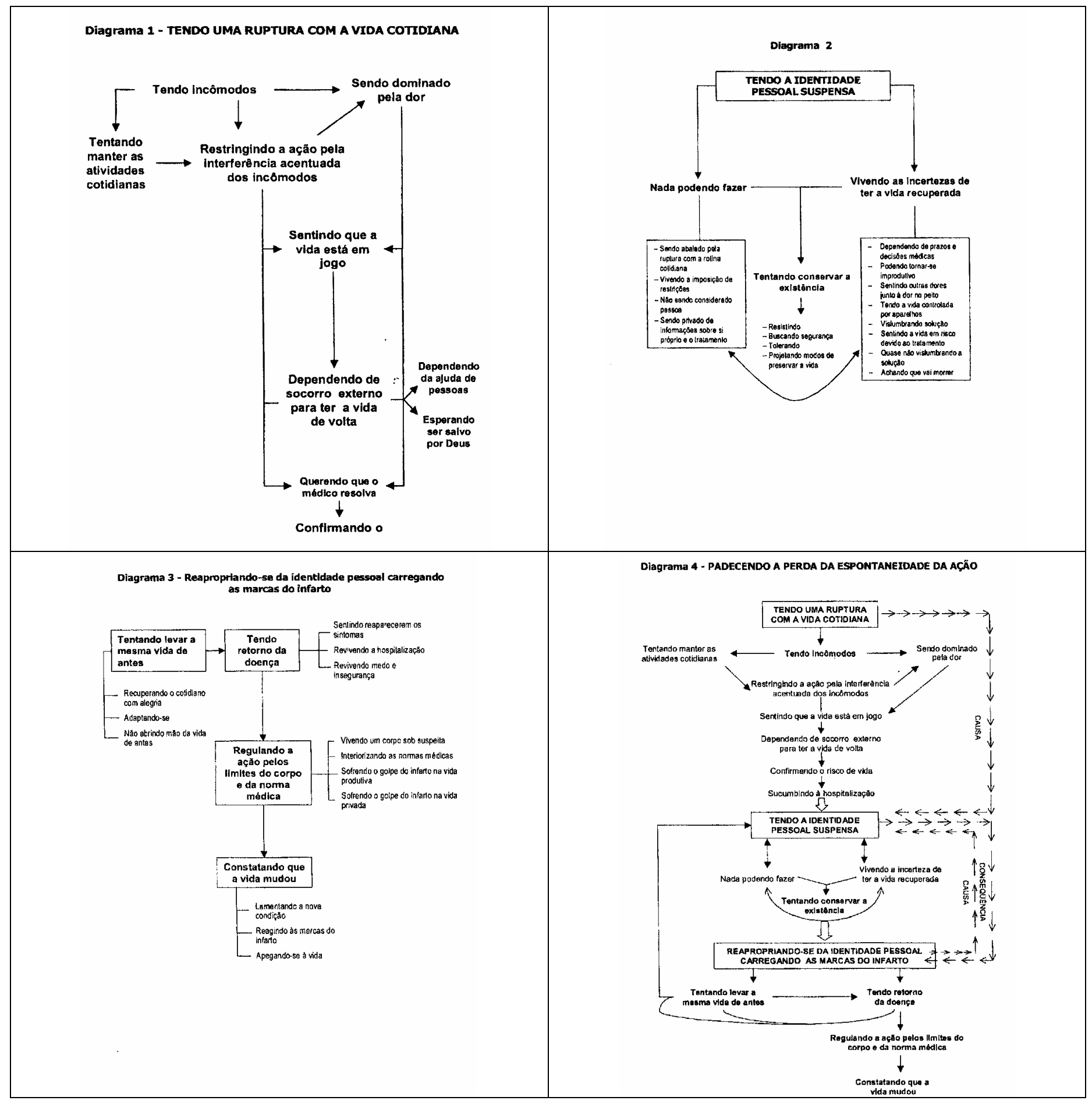

